\title{
Catheter-Directed Thrombolysis for Occluded Central (Ascending Aorta-to-Pulmonary Artery) Shunts: Importance of Shear Stress-Induced, Platelet-Mediated Thrombosis
}

\section{Thrombolysis and Shear Stress in Central Shunts}

\author{
Dhiraj Singh, MD ${ }^{1,2}$, Steffan Sernich, MD ${ }^{1,2}$, Ernest Siwik, MD ${ }^{1,2}$, Nancy Ross-Ascuitto, MD ${ }^{1,3}$, Carey \\ Celestin, $\mathrm{MS}^{4}$, Robert Ascuitto, PhD, MD ${ }^{1,3}$ \\ ${ }^{1}$ Division of Pediatric Cardiology, Department of Pediatrics, Louisiana State University Health Sciences Center, New Orleans, Louisiana, USA \\ ${ }^{2}$ Division of Cardiology, Children's Hospital of New Orleans, New Orleans, Louisiana, USA \\ ${ }^{3}$ Division of Cardiology, Louisiana State University Healthcare Network, New Orleans, Louisiana, USA \\ ${ }^{4}$ Department of Mechanical Engineering, University of New Orleans, New Orleans, Louisiana, USA
}

\begin{abstract}
A central (ascending aorta-to-pulmonary artery) shunt is a standard palliative operation for infants with cyanotic congenital heart disease. Thrombosis of these shunts can be life-threatening. We report our experience with catheter-directed thrombolysis using recombinant tissue plasminogen activator to locally treat totally occluded central shunts as an alternative to surgery. Ten patients (median age 47 days) successfully underwent the procedure. Following thrombolysis, shunt patency was verified by angiography. The arterial oxygen $\left(\mathrm{O}_{2}\right)$ saturations in $100 \% \mathrm{O}_{2}$ increased from a median value of $55 \%$ to $90 \%$. Major bleeding did not occur in any patients. Computational fluid dynamics was used to identify a relationship between shunt hemodynamics and thrombosis. We retrospectively analyzed blood flow through simulations of these shunts as they would have appeared prior to obstruction. The calculations revealed that flow negotiating "angulated" portions of these central shunts produced wall shear stresses of 157-168 Pa (or $\mathrm{N} / \mathrm{m}^{2}$ ), with shear rates reaching 31,400-33,600/s. These values are easily high enough to initiate platelet activation/aggregation, leading to thrombus formation.
\end{abstract}

We conclude that: 1) catheter-directed thrombolysis can be used to rapidly, effectively, and safely resolve total central shunt occlusion in critically ill neonates and 2) central shunts containing prominent angulation are at risk for developing shear stress-induced, plateletmediated thrombosis. This finding is clinically important as this flow-directed process is not affected by prophylactic aspirin against shunt thrombosis.

Copyright @ 2016 Science International Corp.

\section{Key Words}

Occluded central shunts $•$ Wall shear stress $•$ Thrombosis - Shunt thromboylysis

\section{Introduction}

Central (ascending aorta-to-pulmonary artery) shunts have been the standard initial surgical management for many infants and young children with cyanotic congenital heart disease [1-10]. These shunts (polytetrofluoroethylene tubular grafts) are favored (c) 2016 Journal of Structural Heart Disease Published by Science International Corp. ISSN 2326-4004

E-Mail: jshd@scienceinternational.org

http://structuralheartdisease.org/
Accessible online at:

http://structuralheartdisease.org/
* Corresponding Author:

Robert Ascuitto, PhD, MD

Louisiana State University Healthcare Network

Division of Cardiology

3700 St. Charles Ave., New Orleans, LA 70115, USA

Tel.: +1 504 884-0660; E-Mail: nrossascuitto@yahoo.com 
as they generally promote good growth of small pulmonary arteries with minimal vessel distortion [4, 11-12]. However, central shunts have been associated with a high incidence of thrombosis [13-15], which can be a life-threatening or even fatal complication of the procedure. It is, therefore, imperative to rapidly diagnose and effectively treat clotting of a shunt. Shunt thrombosis has traditionally been surgically managed by placing a new graft, although this approach does entail a significant risk to the patient, especially severely ill infants.

In adult patients, percutaneous catheter-directed thrombolysis (CDT) using fibrinolytic agents is increasingly being used as an alternative to surgery to hasten clot resolution in cases of systemic vascular obstruction [16-19]. Typically, this procedure entails infusing thrombolytic drugs, most commonly recombinant tissue plasminogen activator (rTPA or alteplase) directly into the occluded vessel, as an effective treatment to re-establish patency with minimal side effects. Accordingly, specific practice guidelines regarding the use of CDT have been established [20-22]. In contrast, evidence-based recommendations for this form of therapy in infants and young children are not available, and current practice is largely based on previously reported cases [23-28]. Thus, part I of this study consisted of a review of our experience with a cohort of critically ill infants who developed complete central shunt thrombosis. Catheter-based rTPA delivery directly into the shunts was used to relieve the obstructions.

We recently used computational fluid dynamics (CFD) to demonstrate that a viscous fluid (e.g., blood) traversing an "angulated" vessel (or conduit) can produce marked increases in fluid shear stress near the luminal wall (i.e., wall shear stress) where platelets tend to reside [29]. Moreover, it is known that high fluid shear stress can activate platelets, causing them to aggregate and/or bind to coagulation proteins in the blood to form microparticles that serve as precursors for thrombus formation [30]. The shunts considered in this study required an extended length and prominent angulation to connect them from the anterior surface of the ascending aorta to the more posteriorly oriented pulmonary artery (Figure 1). Given this anatomical arrangement, we rationalized that central shunts containing prominent angulation

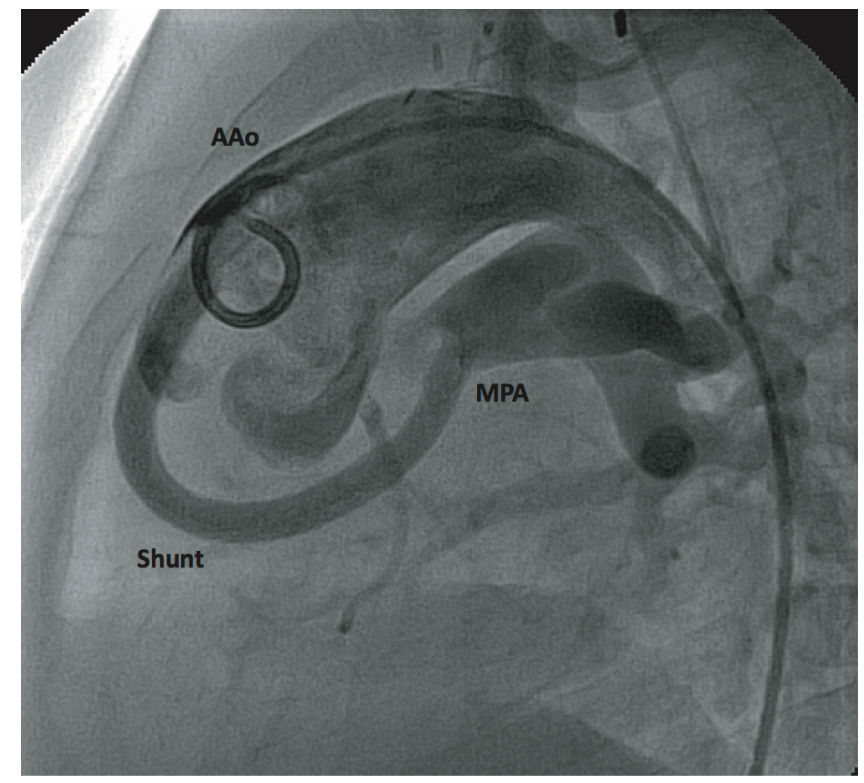

Figure 1. Angiogram performed in the ascending aorta showing an aorta to main pulmonary artery shunt in lateral view. The shunt arose off the anterior surface of the ascending aorta and was then angulated inferiorly and posteriorly to complete the connection to the main pulmonary artery. AAo = ascending aorta; MPA = main pulmonary artery

would be at risk for shear stress-induced, plateletmediated thrombosis. In part II of this investigation, we explored this possibility using: 1) patient-specific angiograms to construct computer simulations of representative central shunts in part I, as they would have appeared prior to becoming obstructed, and 2) CFD to determine whether flow through these angulated shunts could produce wall shear stresses of sufficient magnitude to promote platelet activation/ aggregation. Our goal was to identify a relationship between shunt hemodynamics and thrombosis. An understanding of shear stress-mediated thrombosis is clinically important as this process does not involve thromboxane $A_{2}$ production and hence is insensitive to aspirin (ASA) [29, 31].

\section{Methods}

In part I of this study, we conducted a search of the institutional medical database to identify patients treated with percutaneous CDT to relieve central shunt obstruction between 2008 and 2014. The patients presented with marked arterial blood hemoglobin oxygen $\left(\mathrm{O}_{2}\right)$ desaturation and echocardiographic Doppler flow evidence for total shunt occlusion. Once determined, the patients were taken to the cardiac catheter- 
ization suite where the diagnosis was angiographically confirmed. Infusion of rTPA directly into (or near) the shunt was the primary intervention performed. The institutional protocol for rTPA administration, which is based on a study by Wang et al. [32], was used as a guide to initiate thrombolytic therapy.

All cases were approached retrograde via the aorta. Typically, shunts were engaged by passing a 4-French $(F)$ end-hole catheter over a 0.018-inch guidewire. If the guidewire could not be positioned in the shunt to the operator's satisfaction, the rTPA was initially administered at the mouth of the shunt. In some patients, if the angiographic appearance of the shunt suggested residual clot following thrombolysis, shunt angioplasty was performed with a $(4 \mathrm{~mm} \times 20 \mathrm{~mm})$ Sterling balloon catheter (Boston Scientific, Marlborough, MA, USA). For one patient in extremis, the balloon catheter was used to mechanically advance the clot distally, to at least hasten arterial saturation improvement. The rTPA was then delivered to the distal portion of the shunt and/or the pulmonary arteries until there was angiographic resolution. Care was taken not to dislodge clot into the aorta.

The amount and mode of rTPA delivery to the shunt were based on the extent of thrombus formation, response to the drug, urgency to relieve the obstruction, and prior experience of the physician conducting the procedure. All patients underwent mechanical ventilation with a fraction of inspired $\mathrm{O}_{2}$ of $1.0(100 \%)$. Each individual received $(100 \mathrm{U} / \mathrm{kg})$ of intravenous heparin. Typically, boluses $(0.1-0.5)$ of TPA were given over 5 to 10 minutes with the catheter positioned within or at the orifice of the shunt. Generally, an rTPA dose is not influenced as much by the patient's weight as by the sizes of the shunt and clot, as well as the response achieved. Occasionally, rTPA was diluted in normal saline to a concentration of $(0.5 \mathrm{mg} / \mathrm{mL})$ and infused at a specific rate when a more extended period of time (15-30 min) was desired to administer the drug. Intermittent hand injections of contrast material were periodically used to assess clot resolution progression. Thrombolytic success was defined as restoration of blood flow through the graft with (>95\%) patency as evidenced by angiography. Successful thrombolysis was achieved in all the patients. Following the procedure, patients were placed on an intravenous infusion of heparin at a median dose of $15 \mathrm{U} / \mathrm{kg} / \mathrm{h}$.

In part II of this study, CFD was used to assess wall shear stress magnitude and flow distribution through representative central shunts (cases 2 and 4 ) in part I, as all shunts possessed a similar degree of prominent angulation. Angiograms were performed after thrombolysis to delineate the anatomic features of the unobstructed shunt pathways. The simulated central shunts were constructed using a 3D modeling software computer package (Autodesk Inventor, San Rafael, CA, USA). Once the centerline of a shunt was determined from the angiogram, a constant-diameter, circular cross-section was swept along its course to form the tubular graft (Figure 2, case 2; Figure 3, case 4) [29].

The flow calculations were carried out using the CFD computer program Fluent 14.5 (Ansys, Inc., Lebanon, NH, USA), which solves the 3-D Navier-Stokes and continuity equations using the finite volume method $[29,33]$. The fluid was assumed to be of Newtonian character, with a density of $1,060 \mathrm{~kg} / \mathrm{m}^{3}$ and a viscosity of $5 \times 10^{-3} \mathrm{~kg} / \mathrm{m}-\mathrm{s}$ (hematocrit $\sim 40 \%$ ). The no-slip, zero-flow velocity, boundary condition was imposed
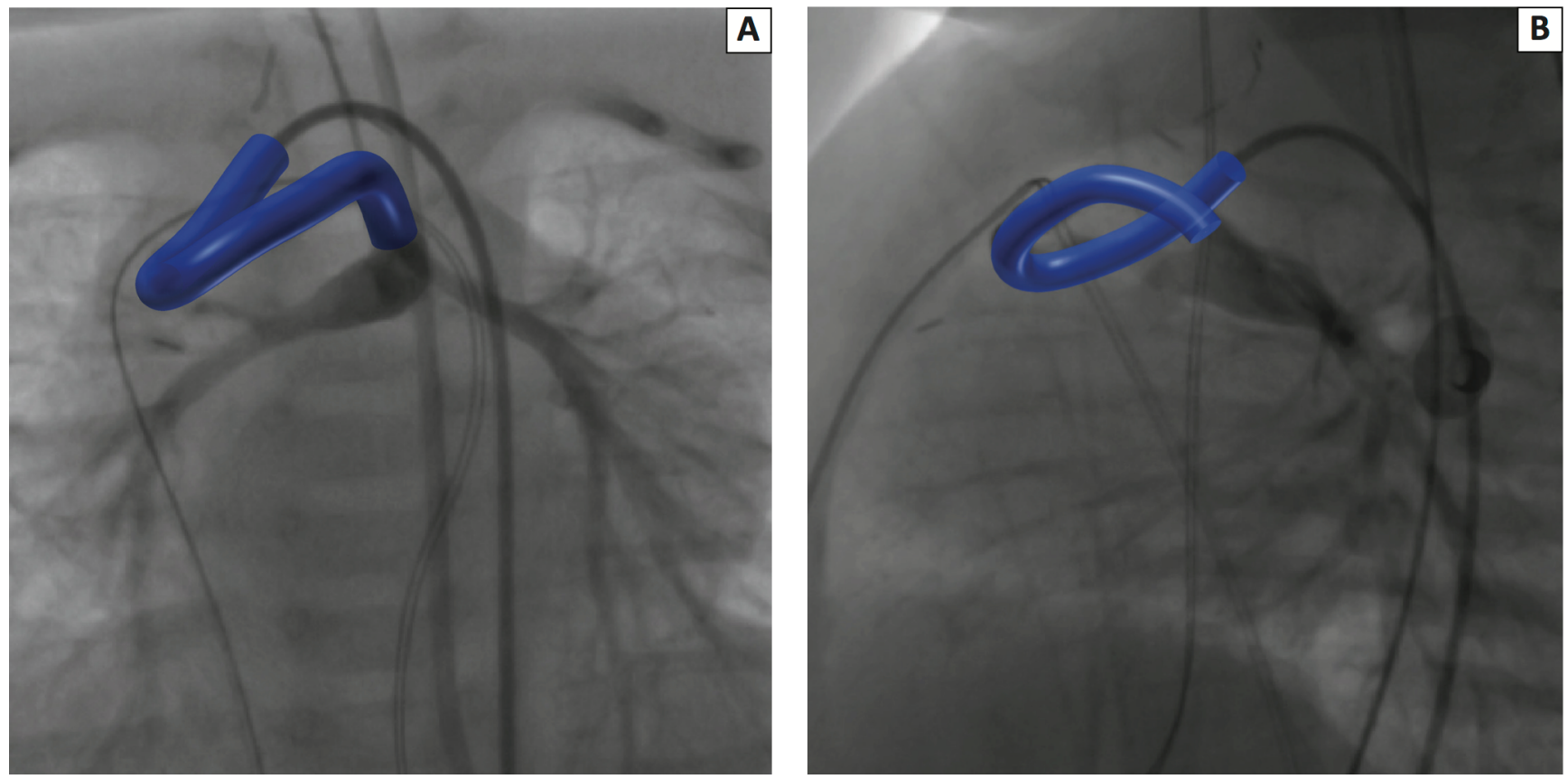

Figure 2. Computer simulation of an ascending aorta to main pulmonary artery shunt (blue) superimposed on the angiogram for case 2 (see Table 1). The shunt is $3.5 \mathrm{~mm}$ in diameter and contains prominent curvature. (Panel A) Anterior and (Panel B) lateral views. Catheter is $4 \mathrm{~F}$. 

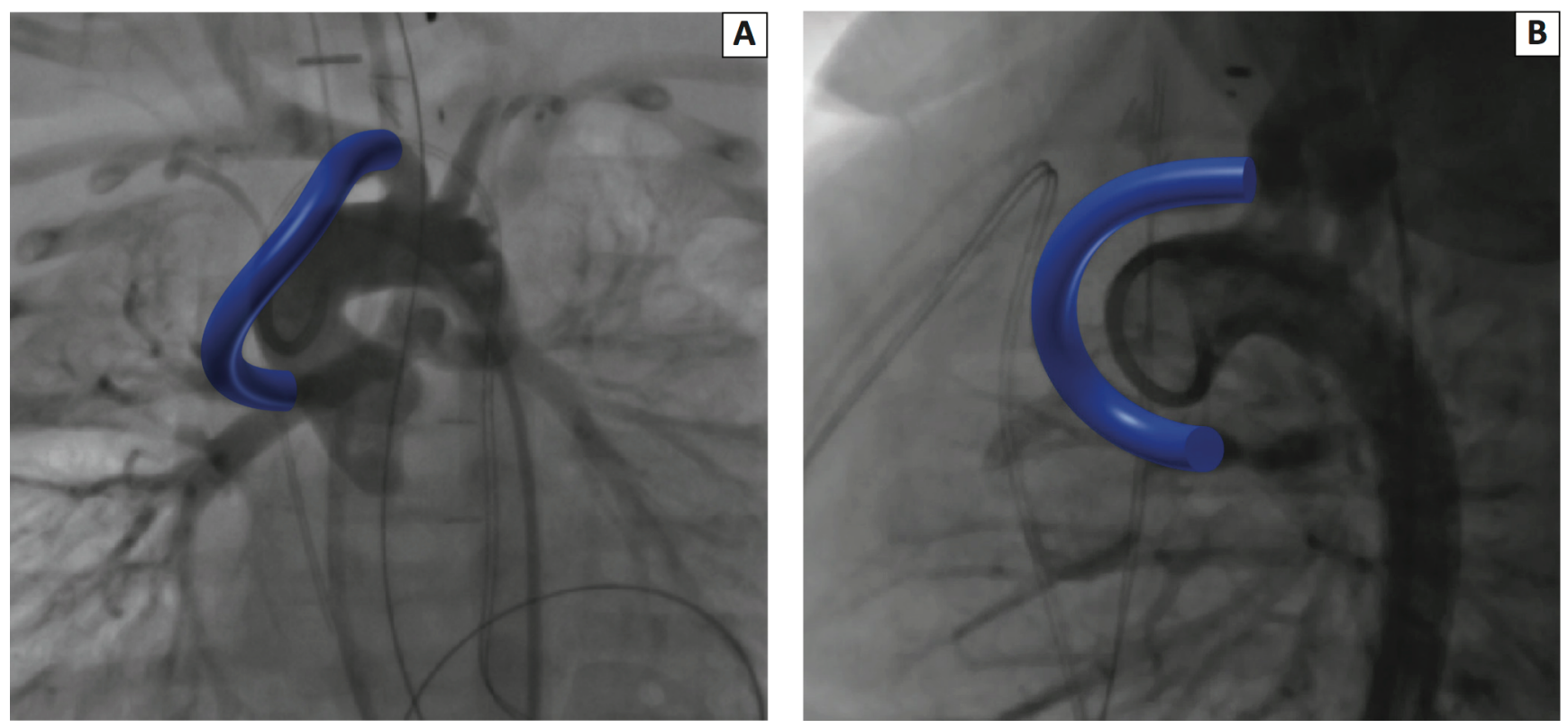

Figure 3. Computer simulation of an innominate artery to right pulmonary artery shunt (blue) superimposed on the angiogram for case 4 (see Table 1). The shunt is $3.5 \mathrm{~mm}$ in diameter and contains prominent curvature. (Panel A) Anterior and (Panel B) lateral views. Catheter is $4 \mathrm{~F}$.

at the luminal wall. For simplicity, steady flow was considered. The overall pressure drop (mean ascending aorta or innominate artery pressure minus mean pulmonary artery pressure) was taken as 6,667 N/m² (50 mm Hg) [29]. Shear stress, which represents the force (per unit area) exerted by flow on the luminal surface of a vessel (or conduit), is expressed in units of pressure (Pascals-Pa or $\mathrm{N} / \mathrm{m}^{2}$ ). For a Newtonian fluid, the shear rate is the ratio of (Shear Stress $\left(\mathrm{N} / \mathrm{m}^{2}\right) /$ Viscosity $\left.(\mathrm{kg} / \mathrm{m}-\mathrm{s})\right)$ and carries units of $(1 / \mathrm{s})$.

\section{Results}

In part I of this study, we assessed the efficacy of using CDT, with rTPA, to treat complete central shunt occlusion. The clinical diagnosis of the patients' congenital heart disease, type of shunt employed and drugs used as prophylaxis against shunt thrombosis, are presented in Table 1. All the shunts that underwent CDT had at least one prominent curvature based on the way they were initially crafted. In $70 \%$ of the cases, the shunts arose off the anterior surface of the ascending aorta and then curved inferiorly and posteriorly to complete the anastomosis to the pulmonary artery. The shunts ranged from $3.0-4.0 \mathrm{~mm}$ in diameter. ASA alone was used in most (70\%) cases as an antiplatelet agent against thrombosis; ASA plus dipyridamole was used in one case, and continuous intravenous heparin infusion was being delivered at the time of thrombosis in two cases (Table 1). Table 2 lists the patients' weights in kilograms $(\mathrm{kg})$ and ages in days (d) at the time of the thrombolysis procedure, as well as the time (d) from shunt placement to thrombosis and the total amounts of rTPA in $(\mathrm{mg} / \mathrm{kg})$ required to resolve the thrombi.

Thrombolytic success was defined as restoration of blood flow through the shunt with no residual thrombus on angiography. The median time from shunt placement to thrombosis was $19 \mathrm{~d}$ (range, 1-47 d). All patients were still in the hospital when their shunts obstructed. The median amount of rTPA required to resolve the thrombus was $0.3 \mathrm{mg} / \mathrm{kg}$ (range, $0.18-5.75 \mathrm{mg} / \mathrm{kg}$ ). The quantity of rTPA required for CDT varied depending on the patient's weight and the extent of thrombus formation. The systemic arterial hemoglobin $\mathrm{O}_{2}$ percent saturation (by pulse oximetry) increased dramatically, from a median value of $55 \%$ to $90 \%$, following thrombolysis. There were three cases in which the thrombus extended beyond the shunt; namely, into the innominate artery (case 4), left pulmonary artery (LPA, case 5), or right pulmonary artery (RPA, case 9). In 
Table 1: Cardiac diagnosis, type of central shunt and diameter $(\mathrm{mm})$ and drug used as prophylaxis against shunt thrombosis.

\begin{tabular}{|c|c|c|c|}
\hline Case & Cardiac diagnosis & Type of shunt and diameter ( $\mathrm{mm})$ & Prophylaxis \\
\hline $1 \mathrm{a}$ & $\begin{array}{l}\text { TS, hypoplastic RV, valvular PS } \\
\text { S/P balloon pulmonary valvuloplasty }\end{array}$ & Asc Ao to MPA (3.5) & ASA \\
\hline $1 b$ & Same & Same & Same \\
\hline 2 & TOF, sub PS, hypoplastic RPA and LPA & Asc Ao to MPA (3.5) & ASA \\
\hline 3 & $\begin{array}{l}\text { TS, hypoplastic RV, sub PS, } \\
\text { S/P augmentation of RVOT }\end{array}$ & Asc Ao to MPA (3.0) & ASA \\
\hline 4 & TA, hypoplastic RV, restrictive VSD, sub PS & Proximal Innominate Artery to RPA (3.5) & ASA \\
\hline 5 & $\begin{array}{l}\text { Dextrocardia, unbalanced AVC, PA, } \\
\text { supracardiac TAPVR (heterotaxia) }\end{array}$ & Asc Ao to LPA (3.5) & ASA \\
\hline 6 & TOF with PA & Asc Ao to MPA (3.5) & ASA and dipyridamole \\
\hline 7 & $\begin{array}{l}\text { TA, hypoplastic RV, restrictive VSD, sub PS } \\
\text { S/P balloon atrial septostomy }\end{array}$ & Asc Ao to MPA (3.0) & ASA \\
\hline 8 & DORV, VSD, sub PS & Asc Ao to MPA (3.5) & Heparin infusion \\
\hline 9 & $\begin{array}{l}\text { PA, VSD, systemic arterial collateral vessels, } \\
\text { hypoplastic native RPA and LPA }\end{array}$ & $\begin{array}{l}\text { Right subclavian artery to RPA (modified } \\
\text { Blalock-Taussig shunt) (4.0) }\end{array}$ & Heparin infusion \\
\hline
\end{tabular}

$\mathrm{TS}=$ tricuspid stenosis; $\mathrm{TA}=$ tricuspid atresia; $\mathrm{PS}=$ pulmonary stenosis; $\mathrm{PA}=$ pulmonary atresia; $\mathrm{S} / \mathrm{P}=$ status post; $\mathrm{RV}=$ right ventricle; $\mathrm{RVOT}=$ right ventricular outflow tract; $\mathrm{AsC} A \mathrm{Ao}=$ ascending aorta; $\mathrm{MPA}=$ main pulmonary artery; $\mathrm{RPA}=$ right pulmonary artery; $\mathrm{LPA}=$ left pulmonary artery; $V S D=$ ventricular septal defect; $A V C=$ atrioventricular canal; TOF = tetralogy of Fallot; DORV = double outlet right ventricle; TAPVR = total anomalous pulmonary venous return; $A S A=a s p i r i n$.

these cases, the additional clot was dissolved as part of the overall thrombolysis procedure. The largest quantity of rTPA $(5.75 \mathrm{mg} / \mathrm{kg}$ or a total of $21.8 \mathrm{mg})$ was required in case 4 , as the thrombus had extended from the shunt through the innominate artery to the origin of the right carotid and right subclavian arteries. The total rTPA infusion time was $88 \mathrm{~min}$. The clots in the LPA (case 5) and RPA (case 9) were in close proximity to the pulmonary ends of their corresponding shunts.

In five of the cases, a $(4 \mathrm{~mm} \times 20 \mathrm{~mm})$ Sterling balloon catheter (Boston Scientific) was used to strip the luminal surface of the graft of any residual clot. In all cases, free flow through the shunts was confirmed by angiography (Figures 4 and 5). Major bleeding, defined as the need for a blood transfusion, did not occur in any of the patients. Although several of the patients received thrombolysis soon after shunt placement, no bleeding occurred at the surgical or catheterization sites. There were no serious complications associated with or following the thrombolysis procedure. There have been no deaths in this group of patients.
In part II of the study, we constructed computer simulations of a representative ascending aorta to main pulmonary artery (MPA) shunt (Figure 2, case 2) and of an innominate artery to RPA shunt (Figure 3, case 4) based on their corresponding post-thrombolysis angiograms. We numerically determined wall shear stress (and shear rate) throughout the simulated shunts and pulmonary arteries. Each studied shunt was $3.5 \mathrm{~mm}$ in diameter. For case 2, the calculated flow rate was $1.6 \times 10^{-5} \mathrm{~m}^{3} / \mathrm{s}(1 \mathrm{~L} / \mathrm{min})$. The corresponding contour plot of wall shear stress is presented in Figure 6 . The distribution of wall shear stress is complex for this convoluted blood flow pathway; it reached its maximum value (168 Pa or $\mathrm{N} / \mathrm{m}^{2}$, red), with a shear rate of $(33,600 / s)$, on the side walls of the shunt where curvature (the apex) is most prominent. The wall shear stress downstream from the apex remained elevated at ( 80 or $\mathrm{N} / \mathrm{m}^{2}$, green) with a shear rate of $(16,000 / \mathrm{s})$, and it attained a secondary maximum (110 Pa or $\mathrm{N} / \mathrm{m}^{2}$, light green) with a shear rate of $(22,000 / \mathrm{s})$. In contrast, an area of low shear stress (10 Pa or $\mathrm{N} / \mathrm{m}^{2}$, dark blue) with a shear rate of $(2,000 / \mathrm{s})$ was also identified, providing an environ- 
Table 2: Patient data associated with the thrombolysis procedures. The columns contain the: weights, in kilograms (kg), and ages, in days (d), at the time of the procedure; time, in days (d) from shunt placement to shunt thrombosis.; total amount of rTPA, in mg/kg, required to resolve the thrombus, and arterial blood $\mathrm{O}_{2}$ saturations (\%) pre- and post-procedure. Additional procedures, see text.

\begin{tabular}{|c|c|c|c|c|c|c|c|}
\hline Case & Weight (kg) & Age (d) & $\begin{array}{l}\text { Time }(d) \\
\text { from shunt } \\
\text { placement } \\
\text { to thrombosis }\end{array}$ & $\begin{array}{l}\text { Total rTPA } \\
\text { (mg/kg) to } \\
\text { resolve the } \\
\text { Thrombus }\end{array}$ & $\begin{array}{l}\text { Additional } \\
\text { procedures }\end{array}$ & $\begin{array}{l}\text { Pre rTPA } \\
\text { arterial } \\
\text { saturations (\%) }\end{array}$ & $\begin{array}{l}\text { Post rTPA } \\
\text { arterial } \\
\text { saturations (\%) }\end{array}$ \\
\hline $1 a$ & 5.0 & 54 & 28 & 0.2 & None & 50 & 80 \\
\hline $1 b$ & 5.1 & 75 & 21 & 0.3 & None & 50 & 80 \\
\hline 2 & 3.0 & 34 & 12 & 0.66 & None & 60 & 80 \\
\hline 3 & 2.8 & 55 & 41 & 0.71 & $\begin{array}{l}\text { Balloon } \\
(20 \times 4 \mathrm{~mm}) \text { of shunt }\end{array}$ & 60 & 80 \\
\hline 4 & 3.8 & 18 & 12 & 5.75 & None & 60 & 90 \\
\hline 5 & 3.0 & 40 & 13 & 0.2 & $\begin{array}{l}\text { Balloon } \\
(20 \times 4 \mathrm{~mm}) \text { of shunt }\end{array}$ & 40 & 90 \\
\hline 6 & 3.5 & 24 & 17 & 0.28 & $\begin{array}{l}\text { Balloon } \\
(20 \times 4 \mathrm{~mm}) \text { of shunt }\end{array}$ & 70 & 90 \\
\hline 7 & 3.3 & 69 & 47 & 0.18 & $\begin{array}{l}\text { Balloon } \\
(20 \times 4 \mathrm{~mm}) \text { of shunt }\end{array}$ & 50 & 90 \\
\hline 8 & 1.5 & 34 & 27 & 1.66 & $\begin{array}{l}\text { Balloon } \\
(20 \times 4 \mathrm{~mm}) \text { of shunt }\end{array}$ & 50 & 90 \\
\hline 9 & 7.9 & 385 & 1 & 0.26 & None & 70 & 90 \\
\hline Median & 3.4 & 47 & 19 & 0.29 & & 55 & 90 \\
\hline
\end{tabular}

rTPA = recombinant tissue plasminogen activator.

ment for flow recirculation.

For case 4, the calculated flow rate was $1.9 \times 10^{-5}$ $\mathrm{m}^{3} / \mathrm{s}$ (1.2 L/min). The corresponding contour plot of wall shear stress is shown in Figure 7. It reached its maximum value of (157 or $\mathrm{N} / \mathrm{m}^{2}$, orange), with a shear rate of $(31,400 / s)$, on the side walls of the shunt, where curvature is most prominent. The wall shear stress downstream from the apex remained high at (80 or $\mathrm{N} / \mathrm{m}^{2}$, green) with a shear rate of $(16,000 / \mathrm{s})$ due to persistent angulation of the graft. For both of these cases, if the shunts are considered to be "straight tubes" of equivalent diameter and length, wall shear stress is dramatically reduced to $30 \mathrm{~N} / \mathrm{m}^{2}$, emphasizing the importance of graft curvature.

\section{Discussion}

Many infants and young children with cyanotic congenital heart disease are highly dependent on the distribution of blood flow between the systemic and pulmonary circulations. Thrombosis of a central shunt can, therefore, be a serious complication, with potentially grave consequences. The clinical presentation of shunt thrombosis is often acute and requires urgent treatment to restore critically needed blood flow to the lungs. Of concern, however, is that the use of systemically administered thrombolytic agents relatively soon after surgical placement of a shunt could lead to serious bleeding at surgical sites or elsewhere. Thus, our goal using CDT was to rapidly deliver rTPA into the clotted shunt, so its action on systemic 

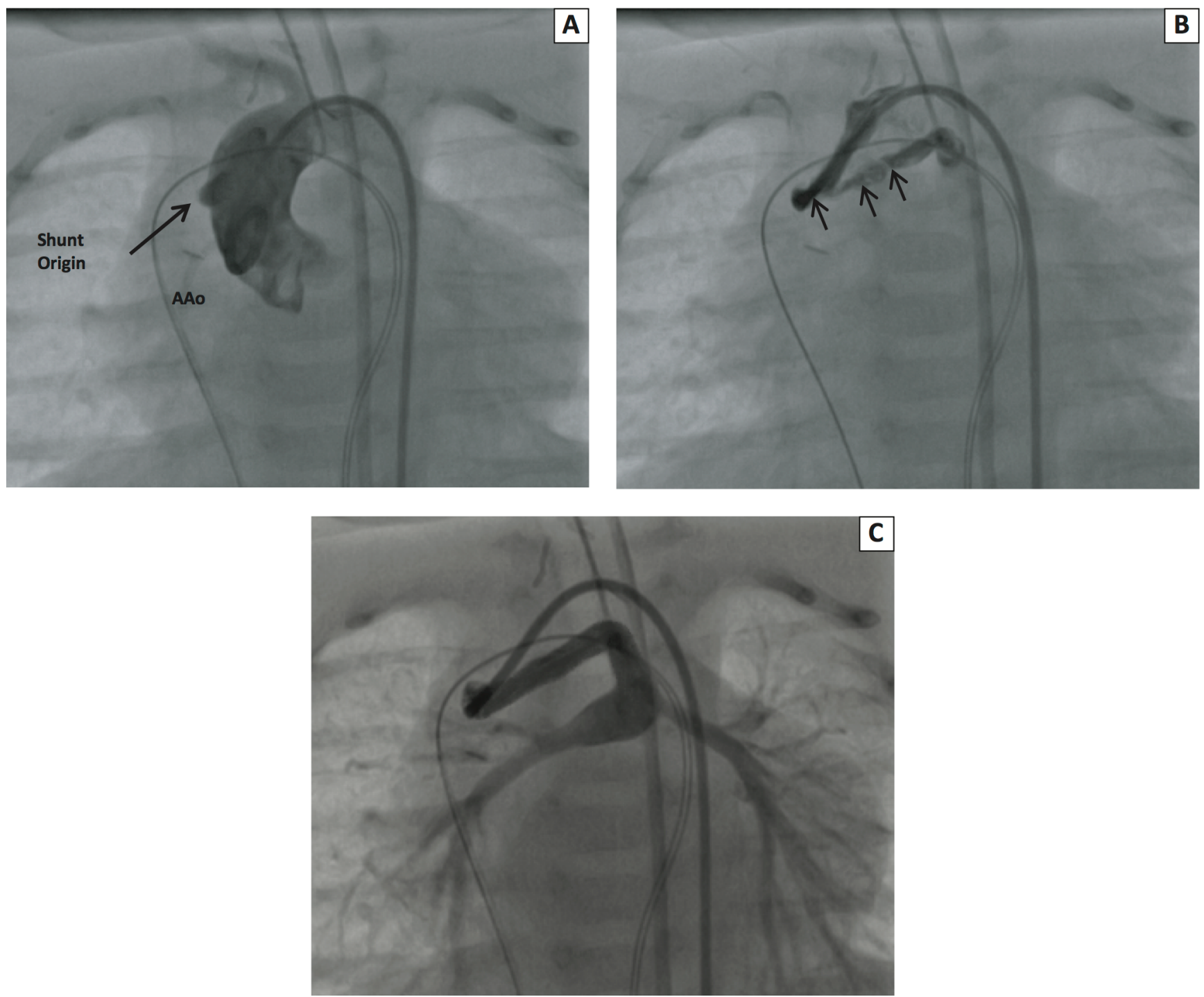

Figure 4. Angiograms during phases of CDT with rTPA for case 2 in the anterior view (also see Figure 2). Panel A. Complete shunt occlusion by thrombus (pre-rTPA). Shunt origin from the ascending aorta (arrow). Note the slight protuberance of the ascending aorta. Panel B. Partial resolution with residual thrombus (arrows). Panel C. Complete resolution of thrombus (post-rTPA). The catheter is $4 \mathrm{~F} . \mathrm{AAO}=$ ascending aorta; $\mathrm{CDT}=$ catheter-directed thrombolysis; rTPA = recombinant tissue plasminogen activator.

circulation would be limited.

An important aspect of part I of this study was to demonstrate that CDT with rTPA can be used to resolve even complete central shunt thrombosis in critically ill infants, with minimal side effects. The median amount of rTPA required to dissolve the thrombus in the graft was $0.3 \mathrm{mg} / \mathrm{kg}$; the corresponding median infusion time was 30 min (range, 2-88 $\mathrm{min}$ ), which would correspond to a rate of $0.6 \mathrm{mg} / \mathrm{kg} / \mathrm{h}$. This amount of rTPA is about half the recommended loading dose of this drug if given systemically [34]. In general, however, the total amount of rTPA required for a thrombolysis procedure will depend on the extent of the thrombus formation, response to the drug, coagulation status of the patient, and complications associated with the procedure. There are several case reports on the local administration of rTPA to treat thrombosis of modified Blalock-Taussig shunts [28, 35-37]. In these cases, resolution of the clotted grafts was achieved 


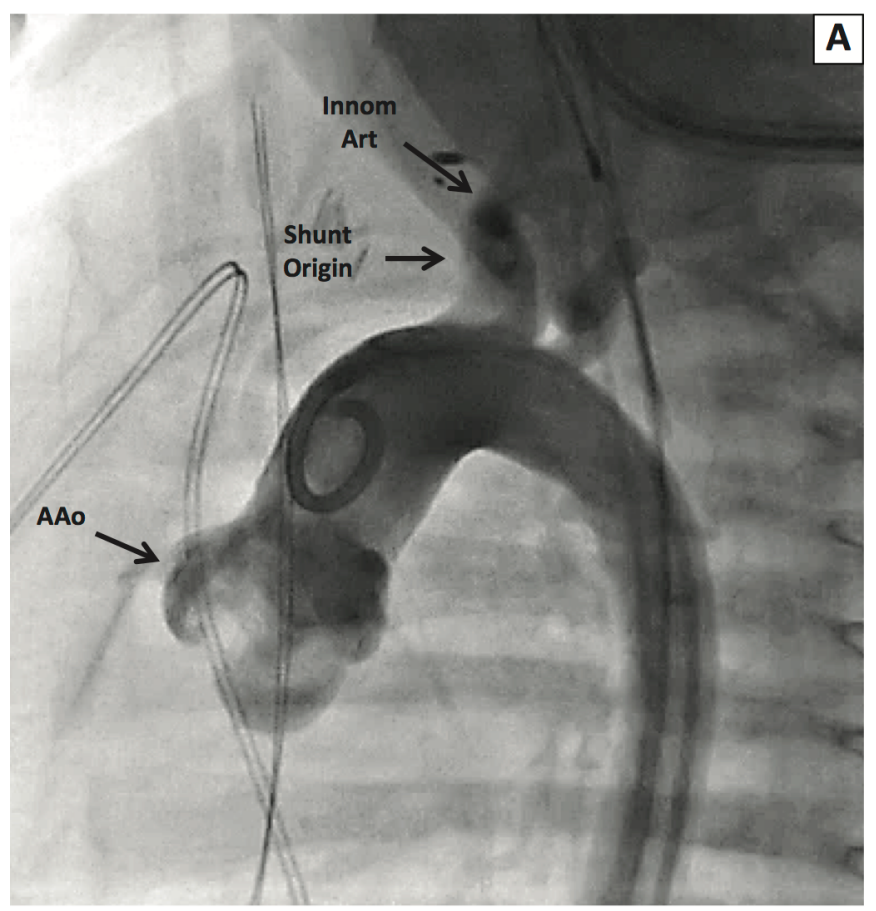

Pre rTPA

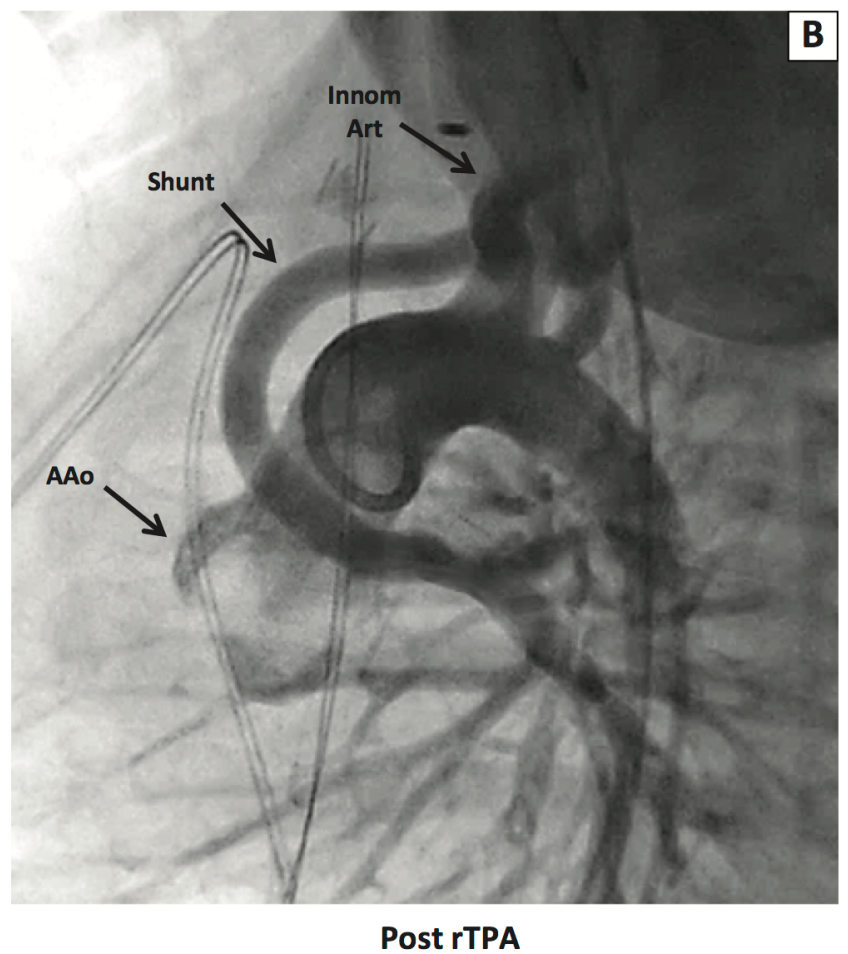

Figure 5. Angiograms pre- and post-CDT with rTPA for case 4 in lateral view (see also Figure 3). Panel A. Complete shunt occlusion by thrombus (pre-rTPA). Shunt origin from the innominate artery (arrow). Panel B. Complete resolution of thrombus (post-rTPA). The catheter is 4F. AAo = ascending aorta; CDT = catheter-directed thrombolysis; Innom Art = innominate artery; rTPA = recombinant tissue plasminogen activator.

without hemorrhagic complications.

In part II of this study, we sought to identify a relationship between central shunt hemodynamics and thrombus formation. When a viscous fluid flows through a vessel (or conduit), it imparts a force (per unit area) on the luminal surface; the so-called wall shear stress. For a Newtonian fluid, wall shear stress directly depends on the fluid's viscosity and its shear rate at the vessel (or conduit) wall, where platelets tend to reside. The interaction of blood flow shearing forces with platelet surfaces is considered the primary mechanical factor responsible for initiating pathologic thrombosis in the arterial system. High shear stress (or shear rate) induces conformational changes in platelet membrane glycoproteins. These changes facilitate the binding of fibrinogen and von Willebrand factor to these glycoproteins, ultimately creating complexes that lead to clot formation [38-40]. For example, Holme et al. [30] showed that blood platelets become activated and form procoagulant microparticles through aggregation when exposed to a shear stress of $50 \mathrm{~N} / \mathrm{m}^{2}$, with a shear rate of 10,500/s. Ruggeri et al. [41] reported that platelets can undergo aggregation, even independent of activation, at a higher shear stress of $80 \mathrm{~N} / \mathrm{m}^{2}$, with a shear rate of $20,000 / \mathrm{s}$.

In case 2 of part I of this study, wall shear stress reached $168 \mathrm{~Pa}$ (or $\mathrm{N} / \mathrm{m}^{2}$ ) with a shear rate of $33,600 / \mathrm{s}$ at the position of maximum curvature in the graft. Likewise, in case 4, wall shear stress at the greatest curvature rose to $157 \mathrm{~Pa}$ (or $\mathrm{N} / \mathrm{m}^{2}$ ), with a shear rate of $31,400 / \mathrm{s}$. These shear stresses (and shear rates) are easily high enough to support platelet-mediated thrombus formation. We previously demonstrated that increases in wall shear stress encountered when flow traverses a prominent bend or curve in a vessel (or conduit), as shown in red in Figure 6 and orange in Figure 7, arise as a consequence of reactive centrifugal effects creating patterns of recirculating flow in the crosssectional plane of the tube [29, 42-44]. This fluid motion can organize into spiral flow fields that, in their rotational motion, augment local shearing 


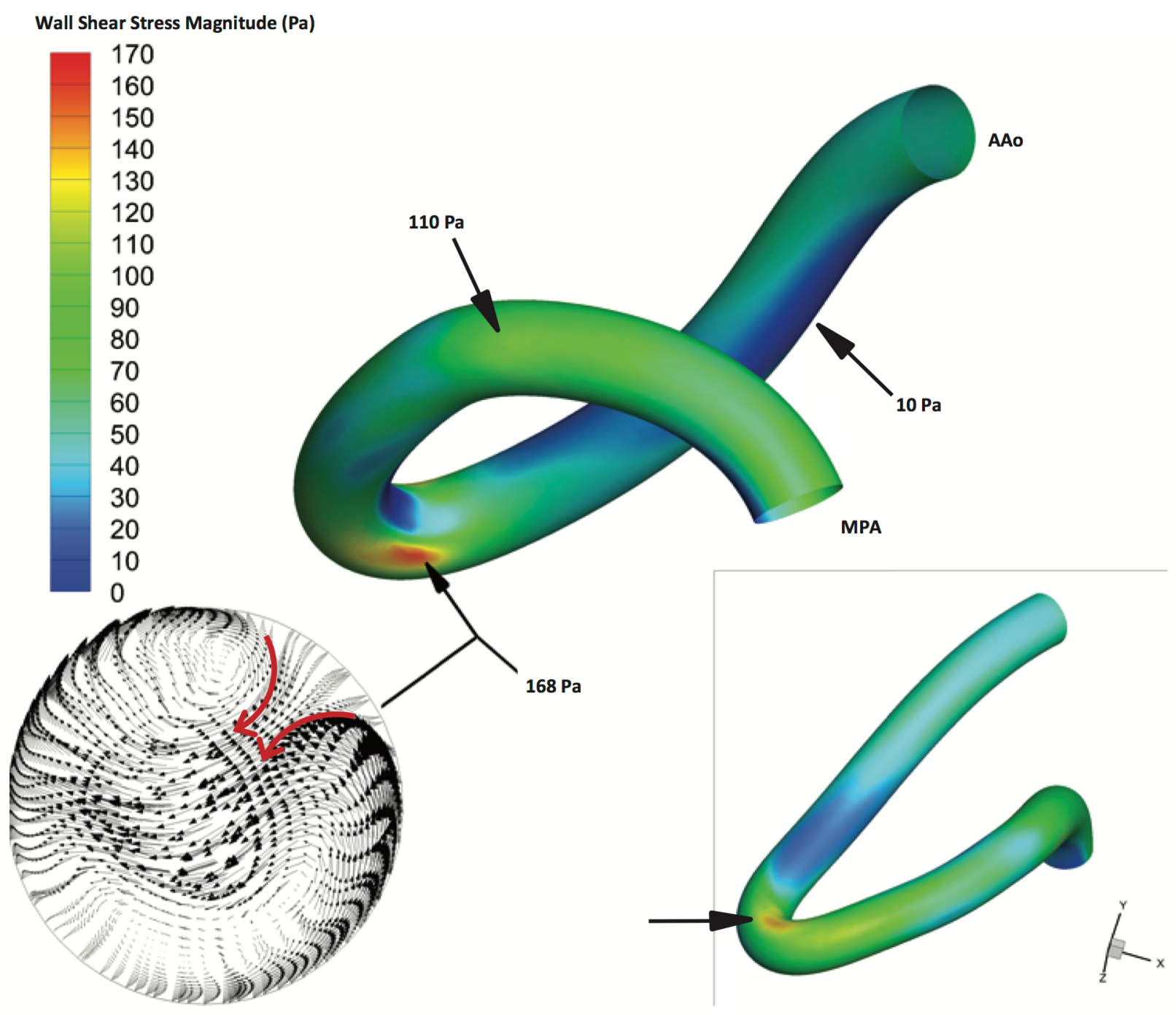

Figure 6. The upper part of the figure shows the wall shear stress contour plot for case 2 in the text (see Figure 2). The shunt has been rotated to better show the regions of high wall shear stress. The maximum wall shear stress (168 Pa or $\mathrm{N} / \mathrm{m}^{2}$, red) is on the side wall of the shunt (arrow). A secondary maximum in wall shear stress (110 Pa or N/m², light green) is indicated by another arrow. An area of low wall shear stress (10 Pa or $\mathrm{N} / \mathrm{m}^{2}$, dark blue) runs along the underside of the shunt (arrow). The lower right side of the figure shows a similar region of high wall shear stress on the contralateral side wall of the shunt (arrow). The lower left side of the figure shows the flow velocity distribution in the cross-sectional plane perpendicular to the central axis of the shunt, in the region of highest wall shear stress. The velocity vectors are projected onto the cross-sectional plane (small dark arrows). The two counterrotating vortices underlie the regions of high wall shear stress, where curvature in the shunt is greatest. The direction of rotation of the fluid composing the vortices is indicated (bold red arrows). AAo = ascending aortic (proximal) end of the shunt; MPA = main pulmonary artery (distal) end of the shunt.

forces on the walls of the tube (see the lower left portions of Figures 6 and 7). In doing so, a hemodynamic process is established that facilitates platelet activation/aggregation.
The surgical approach at our institution is to construct rather long and angulated shunts (Figures 1, 2, and 3) from the anterior surface of the ascending aorta to the more posteriorly 


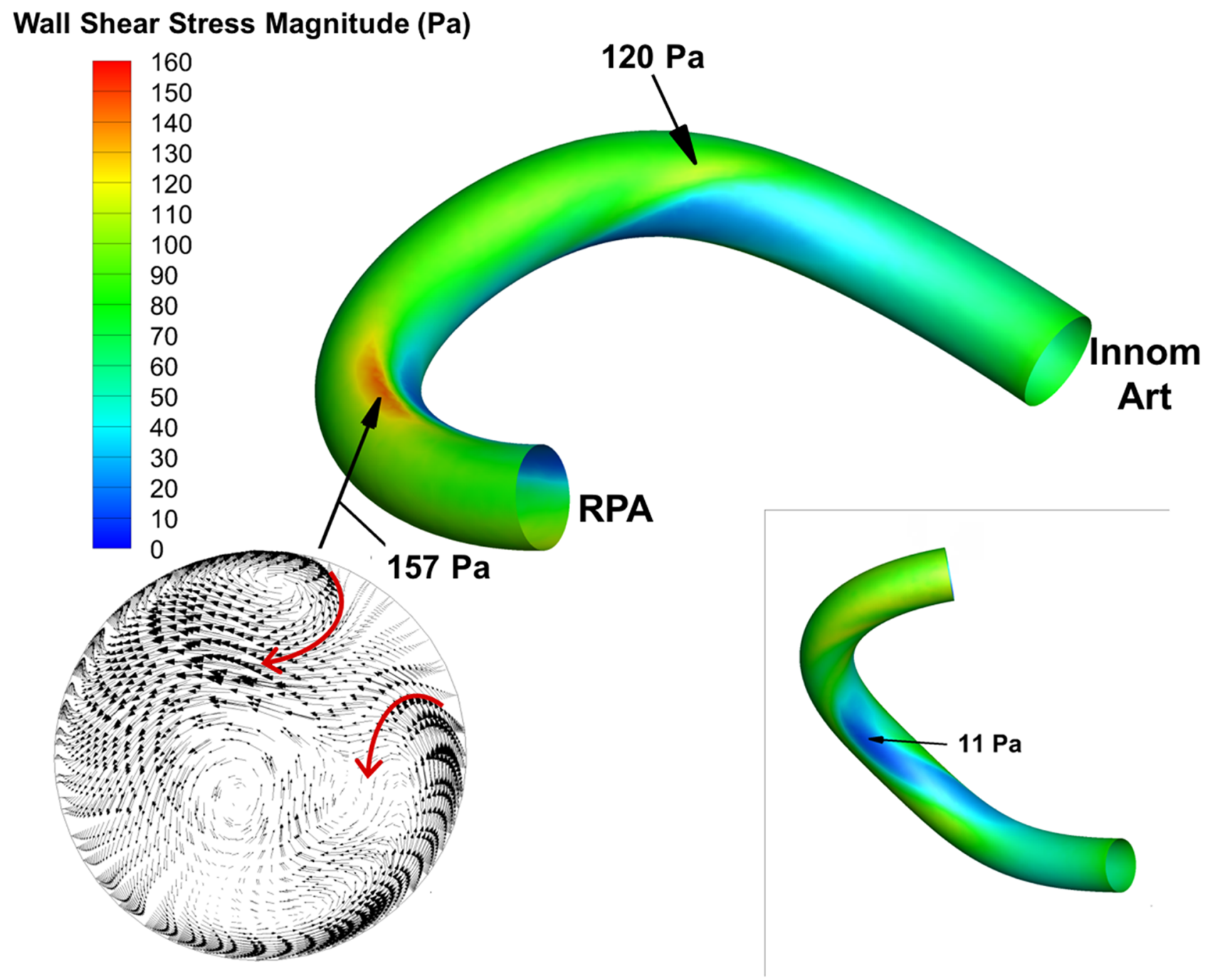

Figure 7. The upper part of the figure shows the wall shear stress contour plot for case 4 in the text (see Figure 3). The shunt has been rotated to better show the regions of high wall shear stress. The maximum wall shear stress ( $157 \mathrm{~Pa}$ or $\mathrm{N} / \mathrm{m}^{2}$, red) is on the side wall of the shunt (arrow). A secondary maximum in wall shear stress (120 Pa or N/m², yellow/green) is indicated by another arrow. The lower right side of the figure shows an area of low wall shear stress ( $11 \mathrm{~Pa}$ or $\mathrm{N} / \mathrm{m}^{2}$, dark blue) that runs along the undersurface of the shunt (arrow). The lower left side of the figure shows the flow velocity distribution in the cross-sectional plane perpendicular to the central axis of the shunt in the region of highest wall shear stress. Velocity vectors are projected onto the cross-sectional plane (small dark arrows). The two counterrotating vortices underlie the regions of high wall shear stress, where curvature in the shunt is greatest. The direction of rotation of the fluid composing the vortices is indicated (bold red arrows). Innom Art = innominate artery (proximal) end of the shunt, RPA = right pulmonary artery (distal) end of the shunt.

oriented pulmonary artery. This type of shunt may lessen pulmonary overcirculation, as most of our patients do not require anticongestive management. However, as demonstrated in a previous study [29] and here, central shunts containing prominent angulation are a risk factor for shear stress-induced platelet-mediated thrombosis. Therefore, contrary to the previous practice of employing ASA alone as prophylaxis against shunt thrombosis, ASA now is being used in conjunction with dipyridamole to prevent clotting [29]. The efficacy of this approach remains to be delineated 
as the hemodynamic substrate fostering high shear stress remains. An alternative surgical approach would be to surgically construct relatively short shunts with minimal curvature, as in modified Blalock-Taussig shunts. This approach should provide adequate relief for the relatively short time periods currently required for initial palliation.

\section{Conclusion}

CDT with rTPA can be used to rapidly resolve central shunt thrombosis in infants and young children, even in the early postoperative period, with minimal side effects. Although this combined clinical and numerical study is limited by the small numbers of patients, our success using CDT to resolve complete central shunt obstruction is encouraging. This procedure appears to be a good therapeutic option to avoid the risks associated with urgent surgery in infants. Moreover, by employing computer simulations of fluid flow through angulated central shunts, we identified a hemodynamic process likely responsible for thrombosis. This mechanism may well be involved in other aorta-to-pulmonary artery shunt occlusions. Prominent changes in fluid direction from shunt angulation and the consequent centrifugal effects on flow through the vessel (or conduit), can create vortices leading to increases in the local wall shear stress (and sheer rate) of sufficient magnitude to initiate platelet activation/aggregation and ultimately thrombus formation. Given that neither the cyclooxygenase pathway nor thromboxane $A_{2}$ production is involved in this hemodynamic process, ASA alone will provide insufficient protection against clotting.

\section{Acknowledgment}

This work was supported in part by a Board of Regents Grant from the State of Louisiana (LSEQF-RD-A-18 Support Fund).

\section{Conflict of Interest}

The authors have no conflict of interest relevant to this publication.

\section{Comment on this Article or Ask a Question}

\section{References}

1. Gazzaniga $A B$, Elliott $M P$, Sperling $D R$, Dietrick WR, Eiseman JT, McRae DM, et al. Microporous expanded polytetrafluoroethylene arterial prosthesis for construction of aortopulmonary shunts; experimental and clinical results. Ann Thorac Surg. 1976;21:322-327. DOI: 10.1016/ S0003-4975(10)64320-2

2. Laks $H$, Fagan $L$, Barner HB, Willman VL. The Blalock-Taussig shunt in the neonate. Ann Thorac Surg. 1978;25:220-224. DOI: 10.1016/S0003-4975(10)63526-6

3. Guyton RA, Owens JE, Waumett JD, Dooley KJ, Hatcher CR, Williams WH. The Blalock-Taussig shunt. J Thorac Cardiovasc Surg. 1983;85:917-922.

4. Lamberti JJ, Carlisle J, Waldman JD, Lodge FA, Kirkpatrick SE, George L, et al. Systemicpulmonary shunts in infants and children. JThorac Cardiovasc Surg. 1984;88:76-81.

5. Bove EL, Sondheimer HM, Kavey REW, Byram CJ, Blackman MS, Parker FB Jr. Subclavian pulmonary artery shunts with polytetrafluoroethylene interposition grafts. Ann Thorac Surg. 1984;37:88-91. DOI: 10.1016/S0003-4975(10)60718-7
6. Davidson JS. Anastomosis between the ascending aorta and the main pulmonary artery in the tetralogy of Fallot. Thorax. 1955;10:348-350. DOI: 10.1136/ thx.10.4.348

7. Jennings RB, Innes BJ, Brickman RD. Use of microporous expanded polytetrafluoroethylene grafts for aorta-pulmonary shunts in infants and complex cyanotic heart disease. J Thorac Cardiovasc Surg. 1978;76:489-494.

8. Ciaravella JM, Midgley FM. Construction of interposition polytetrafluoroethylene ascending aorta-pulmonary artery shunt. Ann Thorac Surg. 1980;29:570-572. DOI: 10.1016/S0003-4975(10)61709-2

9. Donahoo JS, Gardner TJ, Zahka K, Kidd L. Systemic-pulmonary shunts in neonates and infants using microporous expanded polytetrafluoroethylene: Immediate and late results. Ann Thorac Surg. 1980;30:146-150. DOI: 10.1016/S0003-4975(10)61231-3

10. Woolf PK, Stephenson LW, Meijboom E, Bavinck JH, Gardner TJ, Donahoo JS, et al. A comparison of Blalock-Taussig, Waterston, and polytetrafluoroethylene shunts in children less than two weeks of age. Ann
Thorac Surg. 1984;38:26-30. DOI: 10.1016/ S0003-4975(10)62180-7

11. Redo SF, Ecker RR. Intrapericardial aortico-pulmonary artery shunt. Circulation. 1963;28:520-524. DOI: 10.1161/01. CIR.28.4.520

12. Fruccone NJ, Bowman FO, Malm JR, Gersony WM. Systemic-pulmonary arterial shunts in the first year of life. Circulation. 1974;49:508511. DOI: 10.1161/01.CIR.49.3.508

13. Kulik TJ, Foker JE, Lucas RV Jr, Anderson RW, Lock JE. Postoperative hemodynamics in children with polytetrafluoroethylene shunts. Circulation. 1981;64:123-130. PMID: 6166411

14. Amato JJ, Marbey ML, Bush C, Galdieri RJ, Cotroneo JV, Bushong J. Systemic-pulmonary polytetrafluoroethylene shunts in palliative operations for congenital heart surgery. Revival of the central shunt. J Thorac Cardiovasc Surg. 1988;95:62-69. PMID: 2447447

15. Ohuchi H, Okabe H, Nagata N, Koseni K, Kaneko Y, Itoh K. Long-term patency after the Blalock-Taussig operation-comparison between classic and modified shunts [arti- 
cle in Japanese]. Nihon Kyobugeka Gakkai Zasshi. 1996;44:1108-1113. PMID: 8828367

16. Augustinos $P$, Ouriel K. Invasive approaches to treatment of venous thromboembolism. Circulation. 2004;110:127-134. DOI: 10.1161/01.CIR.0000140900.64198.f4

17. Hollingshead $M$, Burke $C T$, Mauro $M A$, Weeks SM, Dixon RG, Jaques PF. Transcatheter thrombolytic therapy for acute mesenteric and portal vein thrombosis. J Vasc Interv Radiol. 2005;16:651-661. DOI: 10.1097/01.RVI.0000156265.79960.86

18. Pianta MJ, Thomson KR. Catheter-directed thrombolysis of lower limb thrombosis. Cardiovasc Intervent Radiol. 2011;34:2536. DOI: $10.1007 / \mathrm{s} 00270-010-9877-z$

19. Engelberger RP, Kucher N. Catheter-bases reperfusion treatment of pulmonary embolism. Circulation. 2011;124:2139-2144. DOI: 10.1161/CIRCULATIONAHA.111.023689

20. Patterson BO, Hinchliffe R, Loftus IM, Thompson MM, Holt PJ. Indications for catheter-directed thrombolysis in the management of acute proximal deep venous thrombosis. Arterioscler Thromb Vasc Biol. 2010;30:669-674. DOI: 10.1161/ATVBAHA.109.200766

21. Karnabatidis D, Spiliopoulos S, Tsetis D, Siablis D. Quality improvement guidelines for percutaneous catheter-directed intra-arterial thrombolysis and mechanical thrombectomy for acute lower-limb ischemia. Cardiovasc Intervent Radiol. 2011;34:1123-1136. DOI: 10.1007/s00270-011-0258-z

22. Meissner MH, Gloviczki P, Comerota AJ, Dalsing MC, Eklof BG, Gillespie DL, et al. Early thrombus removal strategies for acute deep venous thrombosis: clinical practice guidelines of the Society for Vascular Surgery and the American Venous Forum. J Vasc Surg. 2012;55:1449-1462. DOI: 10.1016/j.jvs.2011.12.081

23. Dillon PW, Fox PS, Berg CJ, Cardella JF, Krummel TM. Recombinant tissue plasminogen activator for neonatal and pediatric vascular thrombolytic therapy. J Pediatr Surg. 1993;28:1264-1269; discussion 1268-1269. DOI: 10.1016/S0022-3468(05)80310-0

24. Greenway A, Massicotte MP, Monagle P. Neonatal thrombosis and its treatment. Blood Rev. 2004;18(2):75-84. DOI: 10.1016/ S0268-960X(03)00042-0

25. Temple $M$, Williams $S$, John $P$, Chait $P$, Connolly B. Percutaneous treatment of pediatric thrombosis. Eur J Radiol. 2005;53:14-21. DOI: $10.1016 /$ j.ejrad.2004.07.020

26. Giglia TM, Massicotte MP, Tweddel JS, Barst RJ, Bauman M, Erickson CC, et al. Prevention and treatment of thrombosis in pediatric and congenital heart disease: a scientific statement from the American Heart Association. Circulation. 2013;17;128:2622-2703. DOI: 10.1161/01. cir.0000436140.77832.7a

27. Bavare AC, Naik SX, Lin PH, Poi MJ, Yee $\mathrm{DL}$, Bronicki RA, et al. Catheter-directed thrombolysis for severe pulmonary embolism in pediatric patients. Ann Vasc Surg. 2014;28:1794.e1-e7. DOI: 10.1016/j. avsg.2014.03.016

28. Patange A, Blake J, Gowda S. Complete Blalock-Taussig shunt obstruction in $<24$ hours post-operative period in a neonate treated emergently using transcatheter angioplasty and low dose local recombinant TPA. Catheter Cardiovasc Interv. 2014;83:964-967. DOI: 10.1002/ccd.25281

29. Celestin C, Guillot M, Ross-Ascuitto N, Ascuitto R. Computational fluid dynamics characterization of blood flow in central aorta to pulmonary artery connections: importance of shunt angulation as a determinant of shear stress- induced thrombosis. Pediatr Cardiol. 2015;36:600-615. DOI: 10.1007/s00246-014-1055-7

30. Holme PA, Orvim U, Hamers MJ, Solum NO, Brosstad FR, Barstad RM, et al. Shear-induced platelet activation and platelet microparticle formation at blood flow conditions as in arteries with severe stenosis. Arterioscler Thromb Vasc Biol. 1997;17:646-653. DOI: 10.1161/01.ATV.17.4.646

31. Maalej N, Folts JD. Increased shear stress overcomes the antithrombotic platelet inhibitory effect of aspirin in stenosed dog coronary arteries. Circulation. 1996;93:12011205. DOI: 10.1161/01.CIR.93.6.1201

32. Wang $M$, Hays $T$, Balasa V, Bagatell $R$, Gruppo R, Grabowski EF, et al. Low-dose tissue plasminogen activator thrombolysis in children. J Pediatr Hematol Oncol. 2003;25:379-386. DOI: 10.1097/00043426200305000-00006

33. Munson BR, Young DF, Okiishi TH. Fundamentals of Fluid Mechanics, $4^{\text {th }}$ Edition. Hoboken, NJ: John Wiley \& Sons, Inc.; 2002, p. 350-352.

34. Newall F, Browne $M$, Savoia $H$, Campbell J, Barnes C, Monagle P. Assessing the outcome of systemic tissue plasminogen activator for the management of venous and arterial thrombosis in pediatrics. J Pediatr Hematol Oncol. 2007;29:269-273. DOI: 10.1097/MPH.0b013e318047b78b

35. Ries M, Singer $H$, Hofbeck M. Thrombolysis of a modified Blalock-Taussing shunt with recombinant tissue plasminogen activator in a newborn infant with pulmonary atresia and ventricular septal defect. $\mathrm{Br}$ Heart J. 1994;72:201-202. DOI: 10.1136/hrt.72.2.201
36. Malm TK, Holmqvist C, Olsson CG, Johansson J, Olsson AK, Sandström S, et al. Successful thrombolysis of an occluded modified Blalock shunt three days after operation. Ann Thorac Surg. 1998;65: 1453-1455. DOI: 10.1016/S00034975(98)00165-9

37. Moszura T, Zubrzycka M, Michalak K, Rewers B, Dryzek P, Moll J, et al. Acute and late obstruction of a modified Blalock-Taussig shunt: a two-center experience in different catheter-based methods of treatment. Interact Cardiovasc Thorac Surg. 2010;10:727731. DOI: 10.1510/icvts.2009.219741

38. Kroll MH, Hellums JD, McIntire LV, Schafer Al, Moake JL. Platelets and shear stress. Blood. 1996;88:1525-1541. PMID: 8781407

39. Miyazaki $Y$, Nomura $S$, Miyake T, Kagawa $\mathrm{H}$, Kitada $\mathrm{C}$, Taniguchi $\mathrm{H}$, et al. High shear stress can initiate both platelet aggregation and shedding of procoagulant containing microparticles. Blood.1996;88:3456-3464. PMID: 8896411

40. Goto $S$, Salomon DR, Ikeda Y, Ruggeri ZM. Characterization of the unique mechanisms mediating the shear-dependent binding of soluble von Willebrand factor to platelets. J Biol Chem. 1995;270:23352-23361. DOl: 10.1074/jbc.270.40.23352

41. Ruggeri ZM, Orje JN, Haberman R, Federici $A B$, Reininger AJ. Activation-independent platelet adhesion and aggregation under elevated shear stress. Blood. 2006;108:19031910. DOI: 10.1182/blood-2006-04-011551

42. Dean WR. LXXII. The stream-line motion of fluid in a curved pipe (Second Paper). Phil Mag. Series 7. 1928;5:673-695. DOI: 10.1080/14786440408564513

43. Guan X, Martonen TB. Simulations of flow in curved tubes. Aerosol Sci Technol. 1997;26:485-504. DOI: 10.1080/02786829708965448

44. Siggers JH, Waters SL. Steady flows in pipes with finite curvature. Phys Fluids. 2005;17:077102. DOI: 10.1063/1.1955547

Cite this article as: Singh $D$, Sernich S, Siwik E, Ross-Ascuitto N, Celestin C, Ascuitto R. Catheter-Directed Thrombolysis for Occluded Central (Ascending Aorta-to-Pulmonary Artery) Shunts: Importance of Shear Stress-Induced, Platelet-Mediated Thrombosis. Journal of Structural Heart Disease. 2016;2(3):67-78. DOI: http://dx.doi. org/10.12945/j.jshd.2016.002.15 